\title{
Evaluation of Exponential ADC (eADC) and Computed DWI (CDWI) for the Detection of Prostate Cancer
}

\section{Vergleich von exponentiellem ADC (eADC) und berechneten DWI-Bildern (CDWI) zur Diagnose eines Prostatakarzinoms}

Authors

Alois Martin Sprinkart, Christian Marx, Frank Träber, Wolfgang Block, Daniel Thomas, Hans Schild, Guido Matthias Kukuk, Petra Mürtz

Affiliation

Dept. of Radiology, University of Bonn, Germany

Key-words

prostate, MR-diffusion/perfusion, computed DWI, exponential ADC, prostate cancer, MR imaging

received 07.12 .2017

accepted 22.05.2018

Bibliography

DOI https://doi.org/10.1055/a-0637-9980

Published online: 2018

Fortschr Röntgenstr 2018; 190: 758-766

(c) Georg Thieme Verlag KG, Stuttgart · New York

ISSN 1438-9029

Correspondence

Dr. Alois Martin Sprinkart

Dept. of Radiology, University of Bonn,

Sigmund-Freud-Str. 25, 53127 Bonn, Germany

Tel.: ++ 49/2 28/28716651

Fax: $++49 / 228 / 28715598$

Sprinkart@uni-bonn.de

\section{ZUSAMMENFASSUNG}

Ziel Direkter Vergleich verschiedener Methoden zur besseren Erkennung und Differenzierbarkeit von Prostatakrebs in der diffusionsgewichteten Bildgebung (DWI); Vergleich der Ergebnisse mit originalen DWI-Bildern und konventionellen Apparent Diffusion Coefficient (ADC)-Karten.

Material und Methoden In der retrospektiven Studie wurden DWI-Datensätze klinischer Routineuntersuchungen ( $b=0,50,800 \mathrm{~s} / \mathrm{mm}^{2}$, akquiriert bei einer Feldstärke von $3 \mathrm{~T}$ ) von 104 Patienten mit nachfolgender MR gesteuerten Prostata Biopsie analysiert. Für jeden Datensatz wurden exponentielle ADC-Karten (eADC), berechnete DWI-Bilder (cDWI) sowie eADC-Karten für berechnete b-Werte von 2000 und $3000 \mathrm{~s} / \mathrm{mm}^{2}$ erstellt. Für jede der insgesamt 123 Läsionen wurden Kontrast (CR) und Kontrast-zu-Rausch Verhältnis (CNR) bestimmt. Unterschiede hinsichtlich CR und CNR zwischen den verschiedenen Bildtypen bei malignen Läsionen ( $n=83$ ) sowie Gruppenunterschiede zwischen benignen $(\mathrm{n}=40)$, mit niedrigem Risiko $(\mathrm{n}=53)$ und mit hohem-Risiko $(n=30)$ eingeschätzten Läsionen wurden mittels ANOVA mit Messwiederholung und einfaktorieller Varianzanalyse mit post-hoc Test untersucht. Die Differenzierbarkeit zwischen benignen und malignen Läsionen sowie zwischen malignen Läsionen mit niedrigem und hohem Risiko wurde anhand von Receiver-Operating-Characteristics (ROC)-Kurven bewertet. Ergebnisse CR und CNR waren in den berechneten DWI Bildern und den entsprechenden c_eADC-Karten ( $b=3000$ s/ $\mathrm{mm}^{2}$ und $2000 \mathrm{~s} / \mathrm{mm}^{2}$ ) höher als in den originalen DWI Bildern, in den konventionellen ADC-Karten und in den eADCBildern bei $b=800 \mathrm{~s} / \mathrm{mm}^{2}$. Benigne und maligne Läsionen konnten am besten anhand von Absolutwert und CR in konventionellen ADC-Karten unterschieden werden. Für die Differenzierung zwischen malignen Läsionen mit niedrigem und hohem Risiko erschienen hingegen CR in c_eADC gefolgt von $C R$ in CDWI-Bildern am geeignetsten.

Schlussfolgerung Berechnete cDWI-Bilder und deren entsprechende c_eADC Karten mit b-Werten zwischen 2000 und $3000 \mathrm{~s} / \mathrm{mm}^{2}$ sind zur Detektion von Prostatakrebs besser geeignet als originale DWI-Bilder, konventionelle ADC-Karten und eADC.

\section{Kernaussagen}

- Prostatakrebs kann in originalen DWI800 Bildern unauffällig erscheinen

- Berechnete DWI-Bilder mit b $=2000-3000 \mathrm{~s} / \mathrm{mm}^{2}$ verbessern den Läsion-zu-Normalgewebe-Kontrast bei Prostatakrebs

- Berechnete DWI Bilder zeigen höheren Kontrast als ADC und eADC bei $b=800 \mathrm{~s} / \mathrm{mm}^{2}$

\section{ABSTRACT}

Purpose To directly compare different methods proposed for enhanced conspicuity and discriminability of prostate cancer on diffusion-weighted imaging (DWI) and to compare the results to original DWI images and conventional apparent diffusion coefficient (ADC) maps.

Materials and Methods Clinical routine prostate DWI datasets $\left(b=0,50,800 \mathrm{~s} / \mathrm{mm}^{2}\right.$, acquired at a field strength of $\left.3 \mathrm{~T}\right)$ of 104 consecutive patients with subsequent MR-guided prostate biopsy were included in this retrospective study. For each 
dataset exponential ADC maps (eADC), computed DWI images (cDWI), and additionally eADC maps for computed b-values of 2000 and $3000 \mathrm{~s} / \mathrm{mm}^{2}$ were generated (c_eADC). For each of 123 lesions, the contrast (CR) and contrast-to-noise ratio (CNR) were determined. Differences in the CR and CNR of malignant lesions $(n=83)$ between the different image types and group differences between benign $(n=40)$, lowrisk $(n=53)$ and high-risk $(n=30)$ lesions were assessed by repeated measures ANOVA and one-way ANOVA with post-hoc tests. The ability to differentiate between benign and malignant and between low-risk and high-risk lesions was assessed by receiver operating characteristic (ROC) curve analyses.

Results The CR and CNR were higher for computed DWI and related c_eADC at b=3000 s/mm² and $2000 \mathrm{~s} / \mathrm{mm}^{2}$ compared to original DWI, conventional ADC and standard eADC. For differentiation of benign and malignant lesions, conventional ADC and CR of conventional ADC were best suited. For discrimination of low-risk from high-risk lesions, the $C R$ of C_eADC was best suited followed by the CR of CDWI.
Conclusion Computed cDWI or related c_eADC maps at b-values between 2000 and $3000 \mathrm{~s} / \mathrm{mm} 2$ were superior to the original DWI, conventional ADC and eADC in the detection of prostate cancer.

\section{Key Points}

- Prostate cancer can appear inconspicuous on original DWI800 images

- Computed DWI images at b=2000 - $3000 \mathrm{~s} / \mathrm{mm}^{2}$ improve lesion-to-normal-tissue contrast in prostate cancer

- Contrast in computed DWI is superior to ADC and eADC at $\mathrm{b}=800 \mathrm{~s} / \mathrm{mm}^{2}$

\section{Citation Format}

- Sprinkart AM, Marx C, Träber F et al. Evaluation of Exponential ADC (eADC) and Computed DWI (cDWI) for the Detection of Prostate Cancer. Fortschr Röntgenstr 2018; 190: 758-766

\section{Introduction}

Magnetic resonance imaging (MRI) has become the most powerful imaging technique in prostate cancer diagnosis and has been successfully established in the clinical routine [1]. MRI with subsequent targeted biopsies has been shown to more accurately detect significant prostate cancer than any other technique [2]. Furthermore, a negative predictive value of up to $97 \%$ was reported for clinically significant prostate cancer [3-5]. According to current imaging recommendations, multi-parametric prostate MRI (mpMRI) is based on assessment comprising T2 weighted (T2w), dynamic contrast-enhanced (DCE) and diffusion-weighted imaging (DWI). According to the PI-RADS V2 classification [6, 7], DCE only plays a minor role, while $\mathrm{T} 2 \mathrm{w}$ imaging and DWI provide the major criteria for the diagnosis of a clinically significant prostate tumor.

An important characteristic feature of prostate cancer is the T2 hypointensity relative to the normal glandular tissue. In contrast to malignant tumors in other parts of the body, $\mathrm{T} 2$ relaxation time is shortened in prostate tumors due to the loss of glandular function in cancerous tissue. This causes an "inverse" $T 2$ shinethrough effect in prostate DWI. In conventional prostate DWI using maximum b-values of $800-1000 \mathrm{~s} / \mathrm{mm}^{2}$, diffusion and T2 effects can cancel each other out so that malignant tissue is not always clearly visualized [8]. Two recent studies demonstrated that the sensitivity of tumor detection in DWI was improved when a b-value of 1500 or $2000 \mathrm{~s} / \mathrm{mm}^{2}$ instead of $1000 \mathrm{~s} / \mathrm{mm}^{2}$ was used $[9,10]$.

The acquisition of ultra-high b-values, however, requires an increase in the echo time and has the drawback of an inherently low signal-to-noise-ratio (SNR) [11]. Moreover, these images are prone to severe eddy current distortions caused by the strong motion-sensitizing gradients. Blackledge et al. developed a method for generating high-b value images without actually acquiring them [11]. With this method called computed DWI (cDWI), images with ultra-high b-values are obtained by extrapolation of the signal intensities at lower b-values. The benefit of this approach is a better SNR, a reduction of artifacts and a shorter acquisition time compared to actually acquired high b-value images $[10,12]$. First studies have already shown an enhanced lesion-tobackground contrast and contrast-to-noise ratio in prostate imaging with cDWl at b-values $>1500 \mathrm{~s} / \mathrm{mm}^{2}$ compared to the conventional apparent diffusion coefficient (ADC) and compared to the acquired DWI at the same or lower b-values [13 - 17].

Recently, Park et al. applied a different approach called exponential ADC (eADC) to prostate imaging, again with the aim of avoiding the T2 shine-through effect [18]. The idea of eADC, which was already proposed in 1999 by Provenzale et al., is to normalize DWI images to the signal intensity at $b=0$ [19]. The obtained images should in principle be free of $\mathrm{T} 2$ effects. In a pilot study by Park et al. in which only peripheral zone lesions were analyzed, a significant increase in lesion-to-background contrast ratio of eADC compared to conventional ADC was observed [18]. Further data on the value of eADC in prostate imaging is lacking.

The aim of our study was to directly compare the conspicuity and discriminability of prostate cancer in CDWI and eADC images in a large set of clinical DWI data, and to compare the results to original DWI images and conventional apparent diffusion coefficient (ADC) maps. Additionally, exponential ADC maps for the computed high b-value DWI images were also generated and included in the evaluation.

\section{Materials and Methods}

\section{Subjects}

DWI datasets of 104 consecutive patients with clinical routine MRI of the prostate who subsequently underwent MR-guided prostate 
biopsy were retrospectively analyzed. In total, 123 lesions with histological workup of MRI-guided in-bore biopsy were analyzed. In cases in which more than one core was taken per lesion, the highest Gleason score reported for the lesion was used for lesion classification. Prostate cancer was proven in 83 lesions with a Gleason score of 6/7a/7b/8/9 in 20/33/11/16/3 cases, respectively. 40 lesions were classified as benign tissue in histopathology. 46 malignant and 11 benign lesions were located in the peripheral zone (PZ), 37 malignant and 29 benign lesions were located in the transitional zone (TZ) or the central zone (CZ).

\section{MRI technique}

All examinations were performed on clinical 3.0-T MRI systems equipped with dual-source RF transmission technology (Ingenia, 3.0 T; Philips Healthcare, Best, The Netherlands; gradient system: $80 \mathrm{mT} / \mathrm{m}$ maximum amplitude, $200 \mathrm{~T} / \mathrm{m} / \mathrm{s}$ maximum slew rate) using a 32-channel torso coil with a digital interface for signal detection. A standardized spin-echo echo-planar DWI sequence ( $T R=5000 \mathrm{~ms}, T E=53 \mathrm{~ms}$ ) with three b-values of $0,50,800 \mathrm{~s} /$ $\mathrm{mm}^{2}$ was acquired with diffusion gradients applied in three orthogonal directions. The number of signal averages of the images was 4 for $b=0$ and $50 \mathrm{~s} / \mathrm{mm}^{2}$ and 9 for $b=800 \mathrm{~s} / \mathrm{mm}^{2}$. Isotropic DWI images were directly computed on the scanner. Spectral attenuated inversion recovery was used for fat suppression. Further sequence parameters were: field of view $=320 \times 320 \mathrm{~mm}^{2}$, slice number/thickness $/$ gap $=24 / 4 \mathrm{~mm} / 0 \mathrm{~mm}$, acquired in-plane resolution $=2 \times 2 \mathrm{~mm}^{2}$, echo-planar imaging factor $=65$, half-Fourierfactor $=0.6$, parallel imaging with sensitivity encoding factor $=3$, total acquisition time $=3: 38 \mathrm{~min}$.

\section{Postprocessing}

Based on the original DWI images, the following conventional $A D C$ maps were computed:

- $A_{D C} C_{0 \_800}=\left(\ln \left(S_{0}\right)-\ln \left(S_{800}\right)\right) / 800$ and $A D C_{50 \_800}=\left(\ln \left(S_{50}\right)-\ln \right.$ $\left.\left(S_{800}\right)\right) / 750$, with $S_{0}, S_{50}$ and $S_{800}$ representing the signal intensities at $b=0, b=50$ and $b=800 \mathrm{~s} / \mathrm{mm}^{2}$.

- From $\mathrm{ADC}_{0 \_800}$ and $\mathrm{ADC}_{50 \_800}$, computed DWI images were generated at $b=2000$ and $b=3000 \mathrm{~s} / \mathrm{mm}^{2}: c D_{b_{1} A}=S_{0}{ }^{*} \exp$ $\left(-\mathrm{ADC}_{0 \_800}{ }^{*} \mathrm{~b}\right)$ and $\mathrm{CDWI} \mathrm{I}_{\mathrm{b} \_\mathrm{B}}=\mathrm{S}_{0}{ }^{*} \exp \left(-\mathrm{ADC}_{50 \_800}{ }^{*} \mathrm{~b}\right)$.

To obtain exponential ADC maps, the signal intensity at b $=800 \mathrm{~s} /$ $\mathrm{mm}^{2}$ was normalized to $\mathrm{S}_{0}$ :

- $\mathrm{e} A D C=\mathrm{S}_{800} / \mathrm{S}_{0}[19]$.

In analogy to the eADC of the original DWI data, the cDWI images were also normalized to the signal intensity at $b=0$, yielding a computed exponential ADC:

- c_eADC $=C_{b}=\mathrm{CII}_{\mathrm{b} \_\mathrm{A}} / \mathrm{S}_{0}$.

For each lesion, two regions-of-interest (ROIs) were drawn on the conventional ADC maps and then copied to the calculated and acquired DWI images. The first ROI was placed within the lesion in the hypointense-appearing area of the ADC map. The second ROI was placed in the corresponding contralateral segment as a reference ROI. In cases in which this contralateral segment also showed abnormalities, the reference ROI was placed in healthy- appearing tissue of the same anatomical zone as the lesion (PZ or $T Z / C Z)$. For each lesion, mean signal intensities in the lesion ROI $\left(S_{\text {lesion }}\right)$ and in the reference ROI $\left(S_{\text {normal }}\right)$ as well as the standard deviation of the reference ROI ( $\left.\mathrm{SD}_{\text {normal }}\right)$ were recorded.

Lesion conspicuity was quantified by the contrast ratio (CR) and the contrast-to-noise ratio (CNR) which were defined as

- $C R=\left(S_{\text {lesion }}-S_{\text {normal }}\right) /\left(S_{\text {lesion }}+S_{\text {normal }}\right)$

and

- $C N R=\left(S_{\text {lesion }}-S_{\text {normal }}\right) / S_{\text {normal }}[13,15]$.

All postprocessing steps including the ROI analyses were performed using in-house software written in MATLAB (The MathWorks, Inc., Natick, MA).

\section{Statistical Analyses}

To test for significant differences in CR and CNR between ten different image types $\left(D W I_{800}\left(=S_{800}\right), A D C_{0 \_800}, A D C_{50 \_800}\right.$, eADC,

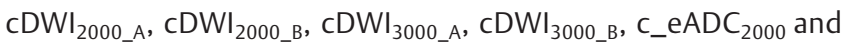
c_eADC 3000 ), a repeated measures analysis of variance (ANOVA) was performed. For this part of the analyses, only malignant lesions (Gleason score $\geq 6, n=83$ ) were included.

In a second step, a one-way ANOVA with post-hoc Bonferroni/ Games-Howell correction (equal/non-equal variances) was performed to test for group differences between benign $(n=40)$, low-risk (Gleason score 6 and 7a, $\mathrm{n}=53$ ) and high-risk (Gleason $7 b, 8,9, n=30$ ) lesions. In addition to the CR values obtained for the ten different image types, the absolute values of the conventional ADCs were also included in this analysis.

Finally, receiver operating characteristic (ROC) curve analyses were performed to assess the ability to differentiate between benign and malignant and between low-risk and high-risk lesions. Again, CR values as well as the conventional ADC values were included in the analysis.

All statistics were performed in SPSS (IBM, Armonk, NY) and MedCalc (Ostend, Belgium).

\section{Results}

Image examples of the original DWI images and the generated maps are shown in - Fig. 1.15 out of 83 malignant lesions had a $\mathrm{CR} \leq 0.05$ in the $\mathrm{DWI}_{800}$ image. In these cases the tumor was inconspicuous or hardly noticeable in original $\mathrm{DWI}_{800}$ due to an inverse $\mathrm{T} 2$ shine-through effect, while the lesion was noticeable in ADC and cDWl images.

The repeated measures ANOVA revealed a significant association of CR and CNR with the image type. The post-hoc tests showed significant differences in $C R$ values between all ten image types with the exception of non-significant differences between $\mathrm{CDWI}_{2000 \_\mathrm{A}}$ and $\mathrm{CDWI}_{2000 \_B}$ and between $\mathrm{CDWI}_{3000 \_\mathrm{A}}$ and $\mathrm{CDWI}_{3000 \_\mathrm{B}}$. The $\mathrm{CR}$ values were highest for $\mathrm{C}_{-} \mathrm{eADC} \mathrm{C}_{3000}$ followed by the $C R$ values of $c D W I_{3000}, c_{-} e A D C_{2000}$ and $C D W I_{2000}$. The $C R$ values of the conventional $A D C_{0 \_800}$ and $A D C_{50 \_800}$ were significantly lower than the CR values of all computed DWIs and computed eADCs. The CR values of conventional ADCs were minimally but significantly higher than the $C R$ values of the related eADC. The lowest $C R$ values were obtained for original $D W_{800}$ 


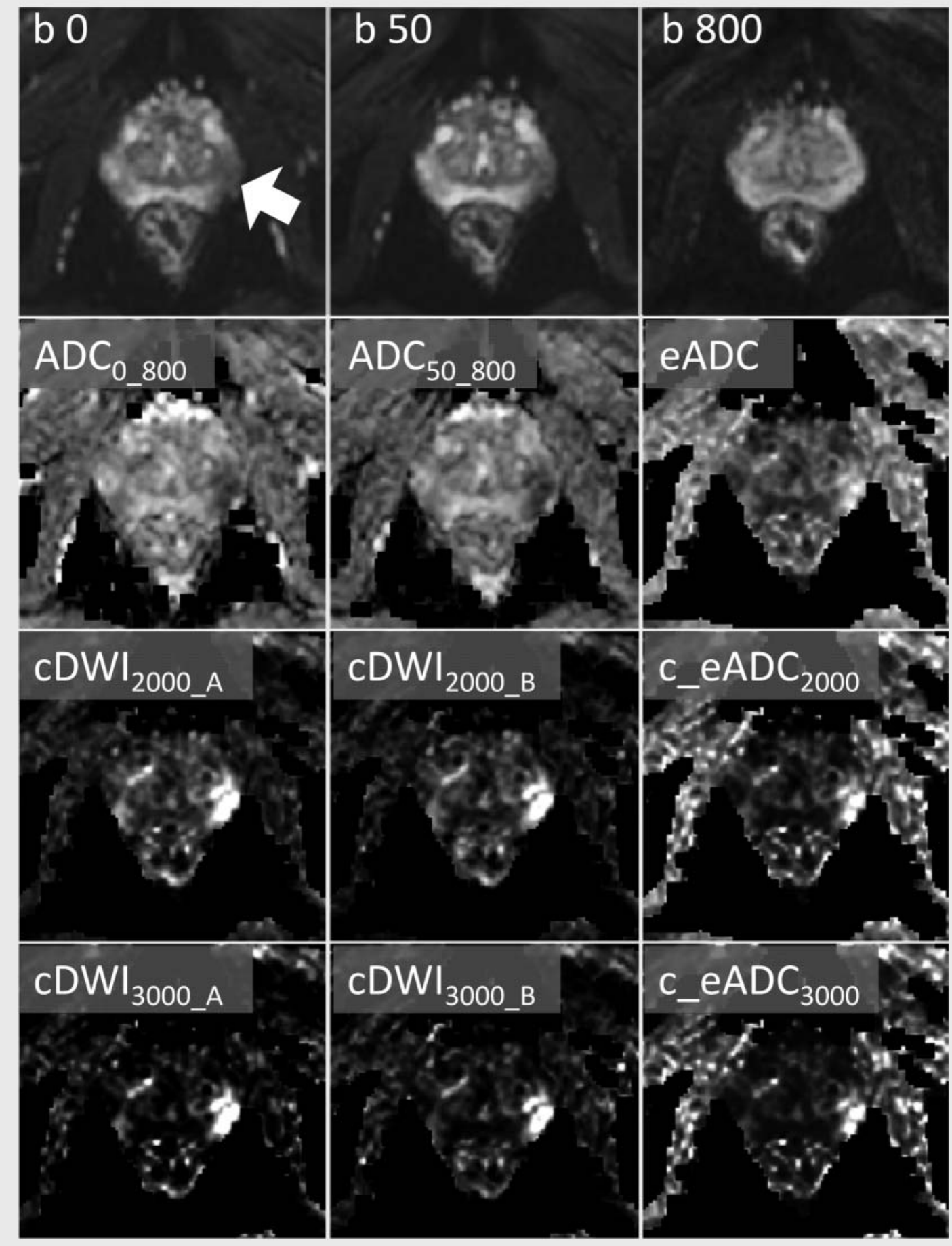

- Fig. 1 Original and computed DWI images of a 72-year-old patient with histopathologically confirmed prostate cancer in segment 6 p (Gleason score 7a). The decrease of the T2 relaxation time in the tumor is noticeable in the b0 image (arrow). Due to the "inverse" T2 shine-through effect, cancerous tissue with restricted diffusion appears inconspicuous on b800 images. The lesion is noticeable in conventional ADC maps, but more conspicuous on all cDWI and c_eADC images due to the high contrast between the lesion and the surrounding prostate tissue. Note that back-

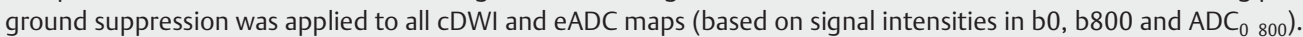

- Abb. 1 Original und berechnete DWI-Bilder eines 72 Jahre alten Patienten mit histopathologisch bestätigtem Protatakrebs in Segment $6 p$ (Gleason Score 7a). Die verkürzte T2 Relaxationszeit im Tumor zeigt sich im b0 Bild (Pfeil). Durch den „inversen“ T2 Durchscheineffekt erscheint das tumoröse Gewebe mit eingeschränkter Diffusion im b800 Bild unauffällig. Die Läsion ist in der konventionellen ADC-Karte erkennbar, sticht in allen cDWI und c_eADC Karten aufgrund des hohen Kontrastes zwischen Läsion und umgebendem Prostatagewebe jedoch noch deutlicher hervor. Bei der Erstellung der CDWI- und eADC- Bilder erfolgte eine Hintergrundunterdrückung (basierend auf den Signalintensitäten in b0, b800 und $\mathrm{ADC}_{0 \_800}$ ). 

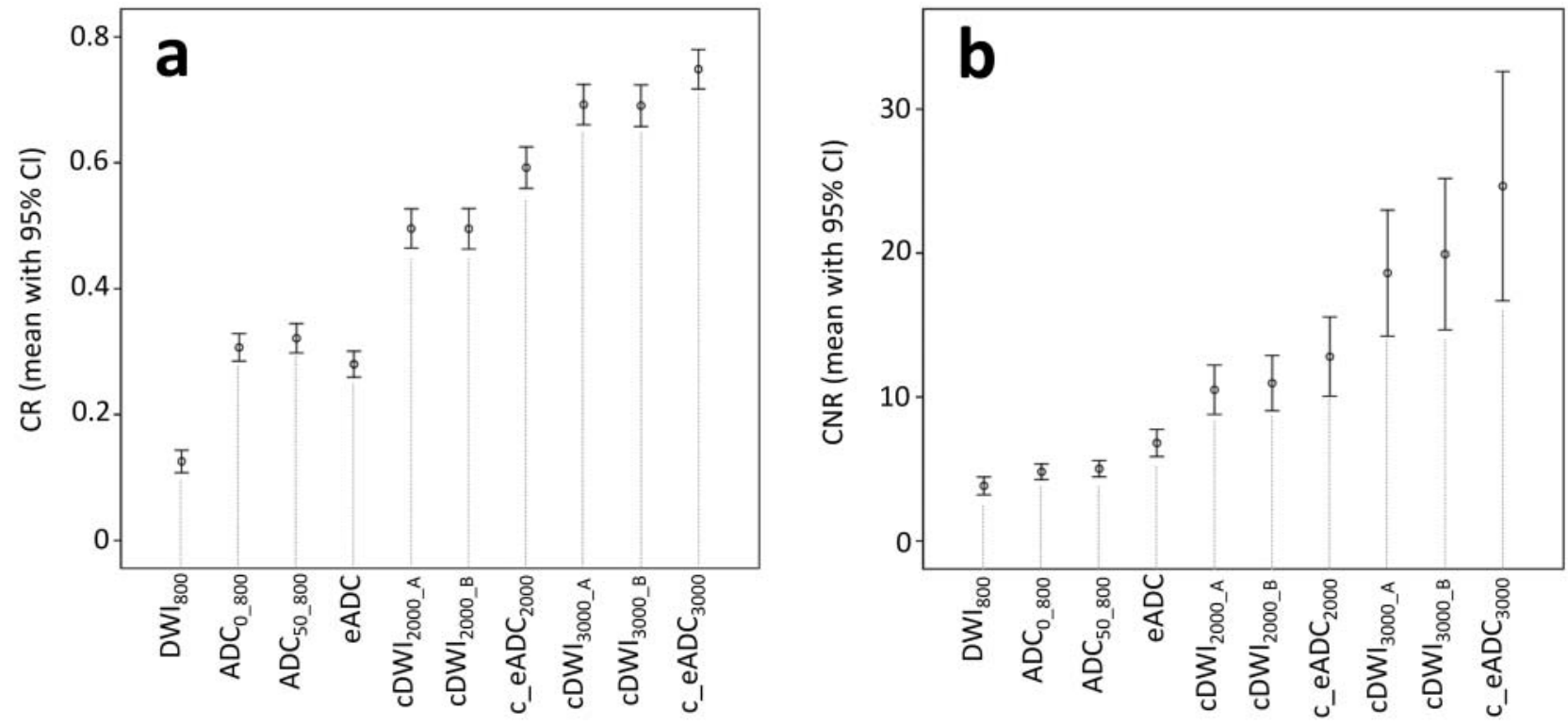

- Fig. 2 a Contrast ratio (CR) and $\mathbf{b}$ contrast-to-noise ratio (CNR) of malignant lesions in ten different image types: acquired DWI ${ }_{800}$, ADC maps computed from $b=0$ and $b=800 \mathrm{~s} / \mathrm{mm}^{2}$ and from $b=50$ and $b=800 \mathrm{~s} / \mathrm{mm}^{2}$, exponential ADC map (eADC), computed DWI images at $b=2000$ and $3000 \mathrm{~s} / \mathrm{mm}^{2}$, and corresponding computed exponential ADC maps.

- Abb. 2 a Kontrastverhältnis (CR) und b Kontrast-zu-Rausch Verhältnis (CNR) der malignen Läsionen in zehn verschiedenen Bildtypen: akquirierte DWI ${ }_{800}$-Bilder, $A D C$-Karten berechnet mit $b=0$ und $b=800 \mathrm{~s} / \mathrm{mm}^{2}$ und mit $b=50$ and $b=800 \mathrm{~s} / \mathrm{mm}^{2}$, exponentielle ADC-Karte (eADC), berechnete DWI-Bilder mit b $=2000$ und $3000 \mathrm{~s} / \mathrm{mm}^{2}$ (cDWI), und die dazugehörigen berechneten exponentiellen ADC-Karten (c_eADC).

$\left(\triangleright\right.$ Fig. 2a). In the original $D W I_{800}$ images, even negative $C R$ values were found in 7 cases.

- Fig. 2 b shows the results of the CNR analysis. The CNR was also markedly higher in all cDWI and c_eADC images compared to conventional $A D C$, eADC and original $D W I_{800}$ images. In contrast to $\mathrm{CR}$, there was no significant difference in CNR between the cDWls and the related/associated c_eADCs. The CNR in eADC images was significantly higher than in conventional ADC maps and in original $\mathrm{DWI}_{800}$ images. No significant differences were found between $\mathrm{DWI}_{800}$ and $\mathrm{ADC}_{0 \_800}$ and between $\mathrm{ADC}_{0 \_800}$ and $\mathrm{ADC}_{50 \_800}$.

The assessment of group differences between benign (group 0 ), low-risk (group 1, Gleason score 6 and 7a) and high-risk (group 2 , Gleason score $7 b, 8,9$ ) lesions revealed a significant association of the investigated parameters (CR values of the ten different image types and absolute ADC values) with the lesion groups ( $\triangleright$ Table 1). There was an increase in the CR values in all image types from group 0 to group 1 to group 2. The group differences between benign and malignant and between low-risk and highrisk groups were significant with the exception of CR in $\mathrm{DWI}_{800}$ and $\mathrm{ADC}_{50 \_800}$ images. In $\mathrm{DWI}_{800}$ images only the difference between the benign and the high-risk group and in $\mathrm{ADC}_{50 \_800}$ maps only the difference between benign and the two malignant groups was statistically significant. For the absolute ADCs significantly higher values were found for the benign group compared to the two malignant groups, but differences between the two malignant groups were not significant.

The ROC analyses revealed that benign $(n=40)$ and malignant $(n=83)$ lesions can be best discriminated by the absolute
$A D C_{0 \_800}$ and by the $C R$ of $A C_{0} 800$ (area under the curves $A \cup C=0.868$ and $A \cup C=0.849$, respectively), followed by the absolute $A D C_{50 \_800}$ and by the $C R$ of $A D C_{50 \_800}$ ( $A U C=0.844$ and $A \cup C=0.828$, respectively). The AUCs for the CRs of all cDWIs, c_eADC and eADC images were all in the range of 0.761 to 0.799 . However, a markedly lower value was found for the CR of $\mathrm{DWI}_{800}(\mathrm{AUC}=0.643)$. All results are listed in $\downarrow$ Table 2 .

For the differentiation between low-risk $(n=53)$ and high-risk $(n=30)$ lesions, the highest AUC was found for the $C R$ of c_eADC 3000 (AUC $=0.711)$, followed by CR of c_eADC 2000 and $C R$ of eADC ( $A U C=0.706$ and $A U C=0.700$, respectively). The $A U C s$ for the CRs of all cDWIs were lower and quite similar (between 0.660 and 0.692 ). The ability to discriminate high-risk and lowrisk lesions by the $C R$ of $A D C_{0 \_800}$ and $A D C_{50 \_800}$ was worst ( $A \cup C=0.657$ and $A \cup C=0.636$, respectively) and not possible for the absolute ADC values (see $>$ Table 3 ).

\section{Discussion}

In this study the conspicuity and discriminability of prostate cancer was evaluated by direct comparison of computed DWI images, standard eADC maps, conventional ADC maps, and computed eADC maps, which has not yet been investigated. The main results were: Computation of DWI images and eADC maps at b-values of 2000 and $3000 \mathrm{~s} / \mathrm{mm}^{2}$ clearly improves the conspicuity of prostate cancer compared to original DWI images with $b=800 \mathrm{~s} /$ $\mathrm{mm}^{2}$, and also compared to conventional ADC and exponential 
- Table 1 Mean ADC values $\left[10^{-6} \mathrm{~mm}^{2} / \mathrm{s}\right]$ and contrast ratio between lesion and normal-appearing prostate tissue in different image types for benign tissue (group 0), low-risk (1) and high-risk (2) prostate cancer.

- Tab. 1 Mittelwert der ADC-Werte $\left[10^{-6} \mathrm{~mm}^{2} / \mathrm{s}\right]$ und Kontrastwerte zwischen Läsionen und normal erscheinendem Prostatagewebe in verschiedenen Bildtypen unterteilt in Läsionen mit benignem Gewebe (Gruppe 0), und Prostatakrebs mit niedrigem (1) und hohem Risiko (2).

\begin{tabular}{|c|c|c|c|c|c|c|c|c|c|}
\hline \multirow[t]{2}{*}{ group } & \multirow{2}{*}{$\begin{array}{l}0 \\
\text { mean }\end{array}$} & \multirow{2}{*}{$\begin{array}{l}(n=40) \\
\text { std. dev. }\end{array}$} & \multirow{2}{*}{$\begin{array}{l}1 \\
\text { mean }\end{array}$} & \multirow{2}{*}{$\begin{array}{l}(n=53) \\
\text { std. dev. }\end{array}$} & \multirow{2}{*}{$\begin{array}{l}2 \\
\text { mean }\end{array}$} & \multirow{2}{*}{$\begin{array}{l}(n=30) \\
\text { std. dev. }\end{array}$} & \multicolumn{3}{|c|}{ p (asymptotic) two-sided test } \\
\hline & & & & & & & 0 vs 1 & 0 vs 2 & 1 vs 2 \\
\hline $\mathrm{ADC}_{0 \_800}$ & 1057 & 148 & 829 & 137 & 811 & 167 & $<0.001$ & $<0.001$ & 1.000 \\
\hline $\mathrm{ADC}_{50 \_800}$ & 983 & 159 & 774 & 143 & 763 & 157 & $<0.001$ & $<0.001$ & 1.000 \\
\hline \multicolumn{10}{|c|}{ Contrast Ratio (CR) } \\
\hline $\mathrm{ADC}_{0 \_800}$ & 0.192 & 0.064 & 0.285 & 0.090 & 0.345 & 0.105 & $<0.001$ & $<0.001$ & 0.029 \\
\hline $\mathrm{ADC}_{50 \_800}$ & 0.205 & 0.080 & 0.301 & 0.101 & 0.356 & 0.108 & $<0.001$ & $<0.001$ & 0.070 \\
\hline$D W I_{800}$ & 0.089 & 0.073 & 0.118 & 0.071 & 0.138 & 0.099 & 0.251 & 0.035 & 0.816 \\
\hline eADC & 0.193 & 0.067 & 0.255 & 0.084 & 0.324 & 0.098 & $<0.001$ & $<0.001$ & 0.006 \\
\hline C_DWI $2000 \_A$ & 0.358 & 0.120 & 0.462 & 0.130 & 0.555 & 0.147 & 0.001 & $<0.001$ & 0.008 \\
\hline C_DWI $2000 \_B$ & 0.359 & 0.124 & 0.464 & 0.134 & 0.550 & 0.155 & 0.001 & $<0.001$ & 0.020 \\
\hline C_eADC 2000 & 0.432 & 0.134 & 0.553 & 0.140 & 0.662 & 0.147 & $<0.001$ & $<0.001$ & 0.002 \\
\hline C_DWI $3000 \_A$ & 0.527 & 0.145 & 0.657 & 0.140 & 0.756 & 0.136 & $<0.001$ & $<0.001$ & 0.008 \\
\hline C_DWI $I_{3000 \_B}$ & 0.526 & 0.157 & 0.658 & 0.146 & 0.749 & 0.146 & $<0.001$ & $<0.001$ & 0.027 \\
\hline c_eADC 3000 & 0.577 & 0.156 & 0.712 & 0.141 & 0.812 & 0.128 & $<0.001$ & $<0.001$ & 0.008 \\
\hline
\end{tabular}

ADC maps at lower b-values. Exponential ADC maps yielded an improved lesion-to-normal contrast ratio over original $\mathrm{DWI}_{800}$ images, but there was no clear benefit over the conventional ADC maps. Differentiation of benign and malignant lesions was best for conventional ADC values and CR values of conventional $A D C$. However, for the discrimination of low-risk from high-risk lesions, $C R$ values of c_eADC were best suited followed by the $C R$ values of $\mathrm{cDWl}$.

There are a few studies with smaller sample sizes that investigated the use of computed DWI in prostate MRI. However, none of those presented a direct comparison between cDWI and eADC for the detection and discrimination of prostate cancer. Furthermore, there is no previous study investigating the use of computed eADC maps.

Based on the existing literature, an increase in lesion-to-normal contrast and contrast-to-noise ratio compared to conventional $A D C$ is only expected with acquired or computed DWI images at b-values higher than $1500 \mathrm{~s} / \mathrm{mm}^{2}$ [13, 14, 16, 20, 21]. cDWI images compared to original DWI images at the same b-value featured a reduced artifact level with similar or better CR and CNR values without additional acquisition time on top of the scan time used to obtain DWI with standard b-values [10, 12, 15, 17, 21].

Feuerlein et al. analyzed cDWI data of 14 patients with computed b-values up to $4000 \mathrm{~s} / \mathrm{mm}^{2}$ and observed an increase in CNR with higher b-values [13]. They recommended the computation of cDWI images with a b-value of at least $2000 \mathrm{~s} / \mathrm{mm}^{2}$ for a significant improvement in tumor conspicuity compared to conventional ADC. On the other hand, Maas et al. noted that extremely high b-values may have some limitations in clinical practice because extremely high and low signal intensities in such images may exceed the dynamic range limits of common viewing systems [12]. This limitation may technically be overcome by the use of a memory depth of 16 instead of 12 bit. However, it remains questionable whether a further numerically detectable increase in contrast-to-noise with extremely high b-values is in fact visually noticeable, since the intensity of the normal prostate tissue is already very low at a b-value of $2000 \mathrm{~s} / \mathrm{mm}^{2}$. Vural et al. computed cDWI images with b-values of 1500, 2000 and $3000 \mathrm{~s} / \mathrm{mm}^{2}$ in 28 patients [16]. Compared to $\mathrm{CDWI}_{2000}$, they found higher $\mathrm{CR}$ values for $\mathrm{CDWI}_{3000}$ images but equal lesion detection rates. Visual assessment of lesion conspicuity revealed no significant differences between $\mathrm{cDWl}_{2000}$ and $\mathrm{cDWl}_{3000}$ images. However, $\mathrm{cDWl}_{2000}$ images provided a better anatomical delineation and were chosen as the most preferred image set. Rosenkrantz et al. computed b-values up to $5000 \mathrm{~s} / \mathrm{mm}^{2}$ and analyzed the lesion-to-peripheral-zone contrast in 49 patients. Again, contrast increased with the b-value, but anatomic clarity and visualization of the capsule decreased. Sensitivity for tumor was highest at $b=1500$ to $2500 \mathrm{~s} / \mathrm{mm}^{2}$ [14]. Motivated by the results of these studies, we computed cDWI images and also c_eADC maps at b=2000 and $3000 \mathrm{~s} / \mathrm{mm}^{2}$ for comparison to original DWI images with $\mathrm{b}=800 \mathrm{~s} / \mathrm{mm}^{2}$, to conventional ADC maps, and to exponential ADC maps. We found improved conspicuity of prostate cancer for the $c D W I$ images. Compared to $b=2000 \mathrm{~s} / \mathrm{mm}^{2}$, a further increase in CR and CNR was found for $b=3000 \mathrm{~s} / \mathrm{mm}^{2}$ in agreement to the previous studies $[14,16]$.

The group of Ueno et al. compared $\mathrm{cDWl}_{2000}$ images computed from six different combinations of acquired b-values [15]. For $b$-value combinations of $b=0,100,500$ with $b=1000 \mathrm{~s} / \mathrm{mm}^{2}$, similar CR values, image quality and lesion conspicuity were obtain- 
- Table 2 Results of the ROC analyses for differentiation of malignant $(n=83)$ and benign $(n=40)$ lesions based on the absolute value of ADC and CR in different image types. AUC: area under the curve with standard error (SE) and $95 \%$ confidence interval (Cl). Criterion is the threshold for which the sum of sensitivity and specificity is maximized.

- Tab.2 Ergebnisse der ROC Auswertung bezüglich Differenzierung von malignen $(n=83)$ und benignen $(n=40)$ Läsionen anhand der Absolutwerte des ADC sowie CR in den verschiedenen Bildtypen. AUC: Fläche unter der ROC Kurve mit Standardfehler (SE) und $95 \%$ Konfidenzintervall (CI). Kriterium: Schwellenwert für welchen die Summe aus Sensitivität und Spezifität maximal ist.

\begin{tabular}{|c|c|c|c|c|c|c|c|c|c|}
\hline malign vs. benign & AUC & SE & $95 \% \mathrm{Cl}$ & $\mathbf{p}$ & criterion & sensitivity & $95 \% \mathrm{Cl}$ & specificity & $95 \% \mathrm{Cl}$ \\
\hline $\mathrm{ADC}_{0 \_800}$ & 0.868 & 0.039 & 0.795 to 0.922 & 0.0001 & $\leq 911.1824$ & 74.7 & $64.0-83.6$ & 87.5 & $73.2-95.8$ \\
\hline $\mathrm{ADC}_{50 \_800}$ & 0.844 & 0.042 & 0.767 to 0.903 & 0.0001 & $\leq 8600.0148$ & 74.7 & $64.0-83.6$ & 85 & $70.2-94.3$ \\
\hline \multicolumn{10}{|l|}{ Contrast Ratio (CR) } \\
\hline $\mathrm{ADC}_{0 \_800}$ & 0.849 & 0.034 & 0.733 to 0.907 & 0.0001 & $>0.2294$ & 78.31 & $67.9-86.6$ & 85 & $70.2-94.3$ \\
\hline $\mathrm{ADC}_{50 \_800}$ & 0.828 & 0.036 & 0.750 to 0.890 & 0.0001 & $>0.2072$ & 86.75 & $77.5-93.2$ & 67.5 & $50.9-81.4$ \\
\hline$D W I_{800}$ & 0.643 & 0.051 & 0.552 to 0.728 & 0.005 & $>0.1226$ & 51.81 & $40.6-62.9$ & 72.5 & $56.1-85.4$ \\
\hline eADC & 0.785 & 0.041 & 0.702 to 0.854 & 0.0001 & $>0.1958$ & 79.52 & $69.2-87.6$ & 67.5 & $50.9-81.4$ \\
\hline C_DWI $2000 \_A$ & 0.779 & 0.041 & 0.695 to 0.848 & 0.0001 & $>0.4227$ & 65.06 & $53.8-75.2$ & 82.5 & $67.2-92.6$ \\
\hline C_DWI $2000 \_B$ & 0.761 & 0.043 & 0.675 to 0.833 & 0.0001 & $>0.3452$ & 84.34 & $74.7-91.4$ & 57.5 & $40.9-72.9$ \\
\hline C_eADC 2000 & 0.792 & 0.04 & 0.710 to 0.860 & 0.0001 & $>0.4318$ & 90.36 & $81.9-95.7$ & 57.5 & $40.9-72.9$ \\
\hline C_DWI $I_{3000 \_A}$ & 0.799 & 0.039 & 0.717 to 0.866 & 0.0001 & $>0.5673$ & 83.13 & $73.3-90.5$ & 70 & $53.5-83.4$ \\
\hline C_DWI $3000 \_B$ & 0.777 & 0.042 & 0.693 to 0.847 & 0.0001 & $>0.579$ & 80.72 & $70.6-88.6$ & 70 & $53.5-83.4$ \\
\hline c_eADC 3000 & 0.797 & 0.04 & 0.715 to 0.864 & 0.0001 & $>0.5916$ & 90.36 & $81.9-95.7$ & 60 & $43.3-75.1$ \\
\hline
\end{tabular}

ed, which was worse for $b$-value combinations of $b=0,100$ with $\mathrm{b}=500 \mathrm{~s} / \mathrm{mm}^{2}$. In our study, we investigated two combinations of b-values ( $b=0$ with 800 and 50 with $800 \mathrm{~s} / \mathrm{mm}^{2}$ ) based on our standard DWI protocol for prostate examinations, and we also obtained very similar results for both variants with respect to $C R$ and CNR.

Interestingly, although we did not observe an increase in $C R$ in eADC images (at $b=800 \mathrm{~s} / \mathrm{mm}^{2}$ ) compared to conventional ADC, exponential ADC images of the computed high b-values led to a slight further increase in CR compared to related CDWI at the same b-value. This result suggests that c_eADC images may be the method of choice to detect prostate cancer with DWI. However, a drawback of eADC and c_eADC maps is the presence of high signal intensities in non-prostate tissue due to the division by $S_{0}$, which is low in tissue surrounding the prostate. This may hamper the detection of small lesions close to the rim of the prostate. Since most prostate cancers are located in the peripheral zone [22], the development of methods for proper suppression of tissue surrounding the prostate would probably enhance the general applicability of c_eADC.

In the second part of the analyses we investigated whether the generation of cDWI images and eADC and c_eADC maps has an advantage over the conventional ADC and original DWI with $\mathrm{b}=800 \mathrm{~s} / \mathrm{mm}^{2}$ for the differentiation of benign and malignant lesions, and to classify malignant lesions into low-risk and high-risk lesions based on the DWI data. Conventional ADC values and CR values of conventional ADC were best suited for the differentiation between benign and malignant lesions (based on the Youden index an $A C_{0 \_800} \leq 911 \mathrm{~s} / \mathrm{mm}^{2}$ yielded the maximum sum of sensitivity $(74.7 \%)$ and specificity $(87.5 \%)$ in this study). For the clas- sification of lesions into low-risk and high-risk lesions, the quantification of CR for c_eADC and cDWI yielded higher AUCs than conventional $A D C$ values and $C R$ values of conventional ADC. This finding is in principle of high clinical relevance since watchful waiting has become an important option for the management of low-risk prostate cancers [23, 24]. However, a valid differentiation between low- and high-risk lesions in the individual case is still not possible even with computed c_eADC or cDWI. Also Agarwar et al. investigated the ability of cDWI to identify low-risk lesions based on DWI data. They analyzed cDWI data of 42 patients with b-values up to $4000 \mathrm{~s} / \mathrm{mm}^{2}$ and suggested cDWI with a b-value of $1600-2000 \mathrm{~s} / \mathrm{mm}^{2}$ as a mean for the selection of active surveillance patients (maximum AUC of 0.75) [20].

These results suggest the following workflow: First, $c D \mathrm{WI}_{2000}$ or e_ADC 2000 images (if proper background suppression is applied) should be read for the detection of suspicious lesions (similar to the inspection of original high-b DWI images in other organs like the brain). Then, the actual ADC value of a suspicious lesion should be measured to aid differentiation between benign and malignant lesions.

Our study has several limitations. Only a small number of patients with a negative biopsy result received a follow-up in our institution so that false-negative classifications cannot be excluded. Moreover, CNR as determined in the present and in previous studies [13] represents only a rough measurement of the contrast-tonoise ratio as the standard deviation in the reference $\mathrm{ROI}$ is also influenced by tissue heterogeneity. The contrast measurements used for the quantification of lesion conspicuity is dependent on the ROI placement. If only hot spot analyses are performed (i. e. measurements are based on very small ROls placed at the most 
- Table 3 Results of the ROC analyses for the differentiation of malignant lesions into high-risk lesions $(n=30)$ and low-risk lesions ( $n=53)$ based on the value of $A D C$ and $C R$ in different image types. See the caption of $\triangleright$ Table 2 for further details.

- Tab.3 Ergebnisse der ROI-Auswertung bezüglich Differenzierung von malignen Läsionen in Läsionen mit hohem Risiko $(n=30)$ und niedrigem Risiko $(n=53)$ anhand der Absolutwerte des ADC sowie CR in den verschiedenen Bildtypen. Weitere Details siehe Legende von $>$ Tab. 2.

\begin{tabular}{|c|c|c|c|c|c|c|c|c|c|}
\hline high vs. low risk & AUC & SE & $95 \% \mathrm{Cl}$ & $\mathbf{p}$ & criterion & sensitivity & $95 \% \mathrm{Cl}$ & specificity & $95 \% \mathrm{Cl}$ \\
\hline $\mathrm{ADC}_{0 \_800}$ & 0.547 & 0.065 & 0.433 to 0.656 & 0.4769 & & & & & \\
\hline $\mathrm{ADC}_{50 \_800}$ & 0.535 & 0.066 & 0.422 to 0.645 & 0.5988 & & & & & \\
\hline \multicolumn{10}{|l|}{ Contrast Ratio (CR) } \\
\hline $\mathrm{ADC}_{0 \_800}$ & 0.657 & 0.064 & 0.545 to 0.758 & 0.0142 & $>0.3614$ & 50 & $31.3-68.7$ & 81.13 & $68.0-90.5$ \\
\hline $\mathrm{ADC}_{50 \_800}$ & 0.636 & 0.065 & 0.524 to 0.739 & 0.0355 & $>0.4019$ & 46.67 & $28.4-65.7$ & 86.79 & $74.7-94.5$ \\
\hline $\mathrm{DWI}_{800}$ & 0.616 & 0.066 & 0.502 to 0.720 & 0.0775 & & & & & \\
\hline eADC & 0.700 & 0.062 & 0.589 to 0.796 & 0.0013 & $>0.3313$ & 56.67 & $37.4-74.5$ & 88.68 & $77.0-95.7$ \\
\hline C_DWI $2000 \_A$ & 0.672 & 0.063 & 0.560 to 0.771 & 0.0068 & $>0.5912$ & 50 & $31.3-68.7$ & 88.68 & $77.0-95.7$ \\
\hline C_DWI $2000 \_B$ & 0.660 & 0.064 & 0.547 to 0.760 & 0.0126 & $>0.6143$ & 43.33 & $25.5-62.6$ & 90.57 & $79.3-96.8$ \\
\hline c_eADC 2000 & 0.706 & 0.062 & 0.595 to 0.801 & 0.0009 & $>0.6814$ & 60 & $40.6-77.3$ & 86.79 & $74.7-94.5$ \\
\hline C_DWI $3000 \_A$ & 0.692 & 0.062 & 0.582 to 0.789 & 0.0021 & $>0.8066$ & 53.33 & $34.3-71.6$ & 88.68 & $77.0-95.7$ \\
\hline C_DWI $3000 \_B$ & 0.676 & 0.063 & 0.564 to 0.775 & 0.0054 & $>0.8102$ & 50 & $31.3-68.7$ & 88.68 & $77.0-95.7$ \\
\hline c_eADC 3000 & 0.711 & 0.061 & 0.601 to 0.806 & 0.0006 & $>0.8939$ & 63.33 & $43.9-80.0$ & 86.79 & $74.7-94.5$ \\
\hline
\end{tabular}

hyperintense area of the lesion), values of CR and CNR may be even higher. Furthermore, it should be noted that cDWI in general does not provide information equivalent to the measured DWI at the same b-value [12]. Only the actual acquisition of high b-values increases the accuracy for the quantification of low ADC values [25] and additionally makes it possible to obtain information about diffusion kurtosis [26]. Finally, prospective studies or retrospective analyses of MRI data with a complete histopathological workup after prostatectomy are required to test whether cDWI in fact increases the detection rate of malignant lesions compared to ADC. To date, this has only been performed by Vural et al. for different b-values but not in comparison to ADC or eADC [16].

In conclusion, computed DWI images clearly improve the conspicuity of prostate cancer compared to original DWI images, conventional $A D C$ and standard $\mathrm{ADC}$ maps calculated from the acquired DWI data. By computing eADC maps from cDWI images, the conspicuity was further increased. However, standard eADC maps did not show any benefit over conventional ADC maps. Conventional $A D C_{0 \_800}$ was best suited for discrimination between benign and malignant lesions, while computed eADC maps may be helpful for discrimination between low-risk and high-risk lesions.

\section{CLINICAL RELEVANCE}

Prostate cancer may be overlooked on original DWI images with $b=800 \mathrm{~s} / \mathrm{mm}^{2}$. Computed DWI images and eADC maps at b-values of 2000 and $3000 \mathrm{~s} / \mathrm{mm}^{2}$ clearly improve the conspicuity of prostate cancer compared to original DWI images and also compared to conventional ADC and exponential ADC maps at lower b-values. Benign and malignant lesions can be best discriminated by conventional ADC.

\section{Conflict of Interest}

The authors declare that they have no conflict of interest.

\section{Widmung}

Diese Arbeit ist Herrn Univ.-Prof. Dr. med. Hans Heinz Schild gewidmet, bei dem wir uns herzlich für die langjährige und stete Unterstützung in allen klinischen und wissenschaftlichen Belangen bedanken möchten.

\section{References}

[1] Franiel T, Quentin M, Mueller-Lisse UG et al. MRT der Prostata: Empfehlungen zur Vorbereitung und Durchführung, MRI of the Prostate: Recommendations on Patient Preparation and Scanning Protocol. Fortschr Röntgenstr 2017; 189: 21 - 28

[2] Bergdahl AG, Wilderäng U, Aus G et al. Role of magnetic resonance imaging in prostate cancer screening: a pilot study within the Göteborg randomised screening trial. Eur Urol 2016; 70: 566-573

[3] Lu AJ, Syed JS, Nguyen KA et al. Negative multiparametric magnetic resonance imaging of the prostate predicts absence of clinically significant prostate cancer on 12-core template prostate biopsy. Urology 2017; 105: 118 - 122. doi:10.1016/j.urology.2017.01.048

[4] Ahmed HU, El-Shater BosailyA, Brown LC et al. Diagnostic accuracy of multi-parametric MRI and TRUS biopsy in prostate cancer (PROMIS): a paired validating confirmatory study. The Lancet 2017; 389: 815-822

[5] Itatani R, Namimoto T, Atsuji S et al. Negative predictive value of multiparametric MRI for prostate cancer detection: Outcome of 5-year followup in men with negative findings on initial MRI studies. Eur J Radiol 2014; 83: $1740-1745$

[6] Weinreb JC, Barentsz JO, Choyke PL et al. PI-RADS Prostate Imaging Reporting and Data System: 2015, Version 2. Eur Urol 2016; 69: 16-40 
[7] Purysko AS, Rosenkrantz AB, Barentsz JO et al. PI-RADS Version 2: A Pictorial Update. RadioGraphics 2016; 36: 1354-1372

[8] Feuerlein S, Boll DT, Gupta RT et al. Gadoxetate disodium-enhanced hepatic MRI: dose-dependent contrast dynamics of hepatic parenchyma and portal vein. Am J Roentgenol 2011; 196: W18-W24

[9] Katahira K, Takahara T, Kwee TC et al. Ultra-high-b-value diffusion-weighted MR imaging for the detection of prostate cancer: evaluation in 201 cases with histopathological correlation. Eur Radiol 2011; 21: 188-196

[10] Rosenkrantz AB, Chandarana H, Hindman N et al. Computed diffusionweighted imaging of the prostate at $3 \mathrm{~T}$ : impact on image quality and tumour detection. Eur Radiol 2013; 23: 3170-3177

[11] Blackledge MD, Leach MO, Collins DJ et al. Computed Diffusion-weighted MR Imaging May Improve Tumor Detection. Radiology 2011; 261: $573-581$

[12] Maas MC, Fütterer ]J, Scheenen TW. Quantitative evaluation of computed high $B$ value diffusion-weighted magnetic resonance imaging of the prostate. Invest Radiol 2013; 48: 779-786

[13] Feuerlein S, Davenport MS, Krishnaraj A et al. Computed high b-value diffusion-weighted imaging improves lesion contrast and conspicuity in prostate cancer. Prostate Cancer Prostatic Dis 2015; 18: 155 - 160

[14] Rosenkrantz AB, Parikh N, Kierans AS et al. Prostate Cancer Detection Using Computed Very High b-value Diffusion-weighted Imaging: How High Should We Go? Acad Radiol 2016; 23: $704-711$

[15] Ueno Y, Takahashi S, Ohno Y et al. Computed diffusion-weighted MRI for prostate cancer detection: the influence of the combinations of b -values. Br J Radiol 2015; 88: 20140738

[16] Vural M, Ertaş G, Onay A et al. Conspicuity of Peripheral Zone Prostate Cancer on Computed Diffusion-Weighted Imaging: Comparison of cDWI ${ }_{1500}, \mathrm{CDWI}_{2000}$, and $\mathrm{CDWI}_{3000}$. BioMed Res Int 2014; 2014: 1 -6
[17] Verma S, Sarkar S, Young J et al. Evaluation of the impact of computed high b-value diffusion-weighted imaging on prostate cancer detection. Abdom Radiol N Y 2016; 41: 934-945

[18] Park SY, Kim CK, Park J] et al. Exponential apparent diffusion coefficient in evaluating prostate cancer at $3 \mathrm{~T}$ : preliminary experience. $\mathrm{Br}$ J Radiol 2016; 89: 20150470

[19] Provenzale JM, Engelter ST, Petrella JR et al. Use of MR exponential diffusion-weighted images to eradicate T2 “shine-through" effect. Am J Roentgenol 1999; 172: 537-539

[20] Agarwal HK, Mertan FV, Sankineni S et al. Optimal high b-value for diffusion weighted MRI in diagnosing high risk prostate cancers in the peripheral zone: Optimal High b-Value DWI for PCa. J Magn Reson Imaging 2017; 45: 125-131

[21] Bittencourt LK. Feasibility study of computed vs measured high b-value (1400 s/mm²) diffusion-weighted MR images of the prostate. World J Radiol 2014; 6: 374

[22] McNeal JE, Redwine EA, Freiha FS et al. Zonal distribution of prostatic adenocarcinoma. Correlation with histologic pattern and direction of spread. Am J Surg Pathol 1988; 12: 897-906

[23] van den Bergh RCN, Ahmed HU, Bangma CH et al. Novel Tools to Improve Patient Selection and Monitoring on Active Surveillance for Low-risk Prostate Cancer: A Systematic Review. Eur Urol 2014; 65: 1023-1031

[24] Habibian DJ, Liu CC, Dao A et al. Imaging Characteristics of Prostate Cancer Patients Who Discontinued Active Surveillance on 3-T Multiparametric Prostate MRI. Am J Roentgenol 2017; 208: 564- 569

[25] Xing D, Papadakis NG, Huang CL et al. Optimised diffusion-weighting for measurement of apparent diffusion coefficient (ADC) in human brain. Magn Reson 1997; 15: 771 - 784

[26] Maurer MH, Heverhagen JT. Diffusion weighted imaging of the prostateprinciples, application, and advances. Transl Androl Urol 2017; 6: 490-498 